\title{
UNIVERSALIZAÇÃO DOS FINS E PARTICULARIZAÇÃO DOS MEIOS: POLÍTICA SOCIAL E SIGNIFICADO NORMATIVO DOS DIREITOS FUNDAMENTAIS
}

\author{
Luis Fernando Schuartz
}

UNIVERSALITY OF PURPOSES AND PARTICULARIZATION OF MEANS: SOCIAL POLICY AND NORMATIVE MEANING OF FUNDAMENTAL RIGHTS

\section{RESUMO}

ESTE ARTIgO ESTÁ DIVIDIDO EM QUATRO PARTES. A PRIMEIRA PARTE DESCREVE, RESUMIDAMENTE, O LUGAR E AS CARACTERÍSTICAS RESERVADOS ÀS POLÍTICAS SOCIAIS NO CENÁRIO PÓS-CRISE QUE O PROF. FARIA CONSIDERA SER O MAIS VEROSSíMIL. NA SEGUNDA PARTE SÃO REMEMORADAS AS INTERDEPENDÊNCIAS ENTRE OS ATRIBUTOS DA EXISTÊNCIA, DA VALIDADE E DA EFICÁCIA DAS NORMAS JURÍDICAS PARA MOSTRAR DE QUE MANEIRA A INEFICÁCIA DE NORMAS, EM PARTICULAR, DAS QUE PRESCREVEM A REALIZAÇÃO UNIVERSAL DE DIREITOS SOCIAIS, PODE REFLUIR E AFETAR OS SEUS CONTEÚDO SEMÂNTICO E FORÇA. A TERCEIRA PARTE ANALISA A RELAÇÃO ENTRE POLÍTICA SOCIAL E DIREITOS FUNDAMENTAIS COMO RELAÇÃO ENTRE MEIOS E FINS QUE POSSUI NOS DIREITOS SOCIAIS O PRINCIPAL ELO DE MEDIACT̃̃O, ESTENDENDO AS CONSEQUÊNCIAS CONSTATADAS NA SEGUNDA PARTE COM RESPEITO AOS DIREITOS SOCIAIS TAMBÉM ÀS PRETENSÕES NORMATIVO-JURÍDICAS REFERENTES À AUTONOMIA PRIVADA E PÚBLICA DOS CIDADÃOS. A QUARTA PARTE FECHA O ARGUMENTO COM UMA BREVE CONCLUSÃO.

\section{PALAVRAS-CHAVE}

UNIVERSALIZAÇÃO DOS FINS E PARTICULARIZAC̣ĀO DOS MEIOS: POLÍTICA SOCIAL E SIGNIFICADO NORMATIVO DOS DIREITOS FUNDAMENTAIS

\section{ABSTRACT}

THIS ARTICLE HAS FOUR SECTIONS. THE FIRST SECTION BRIEFLY DESCRIBES THE PLACE AND THE FEATURES OF SOCIAL POLICIES IN THE POST-CRISIS SCENARIO PROF. FARIA CONSIDERS THE MOST PLAUSIBLE ONE. IN THE SECOND SECTION THE INTERDEPENDENCE BETWEEN THE ATTRIBUTES OF EXISTENCE, VALIDITY AND EFFICIENCY ARE RECOLLECTED IN ORDER TO DEMONSTRATE HOW THE INEFFICIENCY OF NORMS, PARTICULARLY, OF THOSE WHICH PRESCRIBE THE UNIVERSAL REALIZATION OF SOCIAL RIGHTS, CAN REFLOW AND AFFECT ITS SEMANTICAL CONTENT AND STRENGTH. THE THIRD SECTION ANALYSES THE RELATION BETWEEN SOCIAL POLICY AND FUNDAMENTAL RIGHTS AS A RELATION BETWEEN MEANS AND PURPOSES WHICH HAS IN SOCIAL RIGHTS THE MAIN MEDIATION LINK, EXTENDING THE CONSEQUENCES RELATED TO SOCIAL RIGHTS FOUND IN THE SECOND SECTION TO NORMATIVELEGAL PRETENSES REFEREED TO CITIZENS' PUBLIC AND PRIVATE AUTONOMY. THE FOURTH SECTION CLOSES THE ARTICLE WITH A BRIEF CONCLUSION.

\section{KEYWORDS}

UNIVERSALITY OF PURPOSES AND PARTICULARIZATION OF MEANS: SOCIAL POLICY AND NORMATIVE MEANING OF FUNDAMENTAL RIGHTS

\footnotetext{
$\mathrm{S}$ ão várias as questões que "Poucas certezas e muitas dúvidas: o direito depois da crise financeira”, de José Eduardo Faria, coloca à Teoria do Direito, e é provável que a maior parte delas tenha de permanecer sem solução, mesmo depois que a poeira da crise baixar. De fato, talvez a mais profunda lição deixada por enquanto pela experiência da crise não seja política nem tampouco econômica, mas
} 
epistêmica: a falta de previsão dos efeitos econômicos agregados das decisões de demandantes e ofertantes nos mercados de derivativos, nos advertindo acerca dos limites da nossa capacidade de previsão do futuro sob as condições impostas pelo funcionamento de uma economia globalizada e complexa como a economia moderna. Em um mundo no qual o futuro é cada vez menos previsível a partir do passado (BECK, BONSS E LAU, 2003), a tentativa de justificar, por exemplo, mais regulação financeira com fundamento no que teríamos aprendido com aquilo que passou, soa como mistificação tecnocrática que apenas encobre o caráter essencialmente político da discussão e das decisões a tomar.

Esse reconhecimento de um dever de suspensão de pretensões de conhecimento valerá certamente para a conjectura que este artigo apresenta com relação a um desses problemas, a saber, o das implicações normativas da opção de política social que o Prof. Faria caracterizou como:

[...] a substituição da idéia de “direitos universais” por estratégias de "focalização", que concentram os gastos sociais num público-alvo bem definido e selecionado em situação-limite de sobrevivência, de forma a assegurar a maximização da eficiência alocativa de recursos escassos. (FARIA, 2009: 319)

Aquilo que o ensaio do Prof. Faria assinala como um parâmetro - a saber, o "piso social” - do cenário em cuja realização escolheu apostar (dado um conjunto de cenários) figurará aqui como ponto de partida de um exercício intelectual igualmente especulativo, cujo resultado é uma prognose acerca do significado normativo dos direitos fundamentais nesse cenário. O prognóstico é de mudança de tal significado normativo em uma direção perturbadora do equilíbrio entre intuições normativas e teorias que decidiram comprar a pretensão de validade universal dos direitos fundamentais pelo seu valor de face. Embora a referida mudança já fosse visível de uma perspectiva teórica mais geral e logicamente independente da vivência de crises concretas (Schuartz, 2002), uma reorientação política explícita nos moldes delineados pelo Prof. Faria tenderia a difundir e aguçar a percepção de que a situação mudou.

\section{i Políticas sociais dePois da CRISE}

Ao menos desde o avanço da social-democracia e o advento do "Estado de Bem-Estar Social” em vários países europeus após a $2^{a}$ Grande Guerra, até o início dos anos 1980, falar, sem qualificações, em política social, necessariamente incluía referências a políticas universais. Ainda que, já na década de 1970, se mencionasse o "universalismo estratificado" e as "aristocracias de trabalhadores" (MKANDAWIRE, 2007) a fim de marcar impressões de captura de benefícios nominalmente universais por grupos 
privilegiados com maior poder de mobilização política, o tom crítico dessas observações empíricas poderia servir para confirmar - e não refutar - o predomínio do universalismo como orientação normativa e premissa para a justificação das políticas sociais, que se construía em torno da afirmação da existência de uma relação instrumental entre, de um lado, os benefícios prometidos e as intervenções exigidas por tais políticas e, de outro, a promoção da cidadania.

Essa estratégia de justificação, arquitetada, sobretudo, por Thomas H. Marshall na primeira metade da década de 1960 (MARSHALL, 1964), estabelece o bem-estar material do indivíduo como objeto de um direito imediatamente vinculado à sua condição de cidadão e à ideia de emancipação dos riscos e incertezas ligados à sua participação nos mercados de trabalho. O forte apelo normativo dessa estratégia lhe assegurou diversas simpatias e fidelidades. Por exemplo, a noção de "desmercantilização", que desempenha um papel-chave na tipologia dos welfare states proposta por Esping-Andersen, é ainda nitidamente tributária dessa visão (ESPING-ANDERSEN, 1990), assim como as opiniões mais recentes de diversos autores que discutem o balanço entre universalização e focalização nas políticas sociais e os instrumentos de proteção social do trabalhador (ver, e.g., SKOCPOL, 1991; Sen, 1995; MKANDAWIRE, 2007).

É certo que o amparo no normativo foi um convite à problematização do ponto de vista descritivo. A atenção voltou-se para a questão da garantia das condições necessárias - econômicas e políticas - à institucionalização do ideal universalistaemancipatório. Às suspeitas pontuais quanto à parcialidade e ao viés dessa institucionalização no âmbito de Estados específicos juntaram-se as desconfianças estruturais, relacionadas, sobretudo, às restrições de caráter fiscal. O ceticismo acerca da capacidade dos governos de garantir as requeridas coalizões e fazer valer as suas promessas universalistas de bem-estar, dadas as limitações existentes, intensificou a sensação de distanciamento entre desejo e realidade, pressionou governantes a procurarem rotas alternativas para a satisfação dos interesses de seus mandantes e deve ter contribuído para facilitar a aceitação de políticas concentradas em públicos-alvo seletivamente definidos, que se tornaram cada vez mais comuns a partir da década de 1980 (COX, 1998; TENDLER, 2004; TOWNSEND, 2004). Contudo, o universalismo se manteve normativamente robusto não apenas na retórica e nos discursos, mas também, em alguma medida, no âmbito dos processos decisórios de organizações governamentais e não governamentais nacionais e supranacionais - no mínimo, como "ideia reguladora" das atividades de formulação e de implementação das correspondentes políticas públicas, incluindo as "focalizadas" (BEATTIE, 2000; DEACON, 2005). O link para "Política Social” na página inicial do sítio da Organização Internacional do Trabalho (OIT), ilustrativamente, remete o leitor à seguinte afirmação

Access to an adequate level of social protection is recognized by international labour standards and the UN as a basic right of all individuals. It is also widely considered 
to be instrumental in promoting human welfare and social consensus on a broad scale, and to be conducive to and indispensable for social peace and thus improved economic growth and performance (...) Since its creation in 1919, the ILO has actively promoted policies and provided its member states with tools and assistance aimed at improving and expanding the coverage of social protection to all members of the community across the full range of contingencies: basic income security in case of need, health care, sickness, old age and invalidity, unemployment, employment injury, maternity, family responsibilities and death. (OIT $\left.{ }^{1}\right)$.

A derrocada do universalismo tampouco parece iminente se baixamos do mundo dos ideais normativos para o da faticidade das instituições, ainda que, quanto ao último, uma visita à literatura que tem se acumulado no rastro de diagnósticos da suposta retração do welfare state nos países desenvolvidos não possa garantir afirmações suficientemente convergentes. A dificuldade analítica para distinguir corretamente os casos de retrocesso dos casos de acomodação ou calibração inicia-se pela própria caracterização do que seria um Estado de Bem-Estar e dos seus tipos ideais ou "regimes”, passando pela escolha das variáveis apropriadas para medir a evolução das características previamente definidas. As primeiras especulações a respeito de uma crise terminal do Estado de Bem-Estar, da parte tanto de neomarxistas quanto de neoliberais conservadores, aparentemente, não exerceram papel estruturante sobre o debate subsequente, que estaria oscilando entre hipóteses mais contidas diante dos desafios e pressões colocados pelas crescentes internacionalização do sistema econômico e redução dos espaços de ação política dos Estados nacionais, a saber: a hipótese do retrenchment versus a hipótese da mera reestruturação dos welfare states. Uma defesa influente desta segunda hipótese foi proposta por Paul Pierson (1994; 1996; 2001). Nessa mesma direção vão Palier (2002) e Castles (2002). Van Kersbergen (2000) diz que a hipótese que se extrai de um survey da literatura é que, embora o contexto das políticas do Estado de Bem-Estar Social tenha mudado, isso não teria levado à retração do mesmo ou de seus programas. Mais recentemente, Koster (2009) resenhou as conclusões de estudos que investigaram a relação entre globalização e welfare state, que indicariam que este não estaria necessariamente ameaçado por aquela. Rodrik (1998) identifica uma correlação positiva entre grau de exposição de uma economia ao comércio internacional e nível de gastos públicos, e a explica com a hipótese de que os referidos gastos serviriam para prover social insurance ante o risco associado a essa exposição. Para uma discussão sensível às conquistas normativas e às pretensões universalistas do Estado do Bem-Estar, ver Sharpf (2002), que aborda os efeitos da globalização sobre tipos distintos de welfare state, sugerindo que aqueles do tipo escandinavo teriam conseguido preservar intactos os seus programas universais.

A hipótese da retração do Estado de Bem-Estar da Europa Ocidental é defendida, por exemplo, em Korpi (2003), e Korpi e Palme (2003), que usam, para mensuração, 
em vez do volume agregado de gastos públicos com políticas sociais, o nível de desemprego e um índice de reconhecimento de direitos sociais. Essa conclusão - que se alinha à de Clayton e Pontusson (1998), e segundo a qual o componente propriamente universalista do welfare state, que prevê benefícios desvinculados da posição do recipiente no mercado e colados imediatamente a direitos de cidadania, estaria em declínio comparativamente aos demais componentes, quais sejam, o da "seguridade social”, que liga os benefícios à participação do recipiente em uma relação formal de emprego e os faz variar em função de diferenças na qualidade dessa participação (p.ex., no valor total contribuído pelo recipiente durante o período de tempo relevante), e o "assistencialista", no qual a concessão dos benefícios se circunscreve ao conjunto das pessoas que obtiverem rendimentos até determinado limite ("means-tested benefits”). Entretanto, não há sinal de que o declínio irá tão longe a ponto de justificar prognoses sombrias. Sob condições de incerteza e ignorância sobre o futuro, portanto, apostar em uma desinstitucionalização generalizada da ideia de direitos sociais universais pode ser arriscado demais.

A atual crise financeira não alterou esse quadro. Seu impacto esperado, conforme antecipado, é justamente o de solapar a nossa confiança nas pretensões de conhecimento que acompanham prognoses mais ambiciosas, tanto pessimistas quanto otimistas. A crise nos recorda da imprevisibilidade de eventos futuros que se interpõem entre a realidade e nossos planos de ação. Nesse contexto, a fabricação ex post da previsibilidade dos efeitos agregados das decisões dos agentes primariamente envolvidos na gestação da crise - ainda que eventualmente necessária para a imputação de responsabilidades e o enfraquecimento das resistências políticas contra o aumento anunciado do poder das burocracias estatais e transnacionais -, não deve adicionar nem subtrair conhecimento ou esperança aos estoques disponíveis pré-crise para o cumprimento das promessas universalistas institucionalizadas nos países desenvolvidos.

Mas se não existem boas razões para apostar no cenário do abandono da ideia de direitos universais naqueles Estados de Bem-Estar onde ela se encontra institucionalizada juridicamente, o que dizer de países nos quais a ocorrência da referida institucionalização é no mínimo questionável? Particularmente no Brasil, apesar da proclamação nominal de direitos sociais universais no texto constitucional, os melhores argumentos parecem estar do lado dos que suspeitam da sustentabilidade das suas pretensões de eficácia e de força jurídica. Como veremos mais à frente, as implicações dessa suspeita, assumindo que seja justificada, dependerão do tipo de argumento utilizado para sua justificação. Contudo, a existência de uma justificativa razoável, independentemente de qual o seu tipo, já bastaria para tornar atraente a hipótese da "substituição" sugerida pelo Prof. Faria e apresentada logo no início deste artigo.

A hipótese deve ser entendida como afirmando que a "ideia de direitos universais" deixará de funcionar efetivamente como orientação normativa para as decisões de 
política pública adotadas pelos atores relevantes - e não, obviamente, que essa ideia desaparecerá como insumo para expectativas subjetivas, reivindicações coletivas ou declarações de princípios. Ela é abandonada para ceder o lugar a "estratégias de focalização", tipicamente assistencialistas, voltadas exclusivamente a pessoas que se encontrem em "situação-limite de sobrevivência". A propósito, as observações mais críticas constantes, por exemplo, nos artigos citados de Tendler e de Mkandawire, no sentido de um avanço da focalização em detrimento da universalização no âmbito das políticas sociais, referem-se, basicamente, aos países em desenvolvimento. O caso do Bolsa-Família, mencionado pelo Prof. Faria para ilustrar esse ponto, é paradigmático. A condicionalidade das transferências de renda que o Programa prevê só funcionará como mecanismo de inclusão e interrupção do ciclo intergeracional de pobreza quando conjugada com uma política universal de garantia de acesso a serviços de educação e saúde de qualidade. A universalidade na prestação desses serviços é complementar à redistribuição focalizada prevista no Programa, condicionando a sua classificação como uma instância de política social não meramente assistencialista. Consequentemente, na medida em que se descumpre a referida promessa universalista, as expectativas propriamente emancipatórias criadas com o Bolsa-Família sucumbem diante de expectativas concorrentes no espaço das combinações lineares de bom-samaritanismo e clientelismo eleitoreiro. ${ }^{2}$

Negada a complementaridade entre as duas políticas, a migração do universalismo à focalização nos mais pobres aproxima a política social de uma estratégia residualista de intervenção do Estado na economia, tributária de uma concepção de distribuição primária de vantagens materiais fundada na ideia de "justiça de mercado" (Kerstenetzky, 2006). A atuação dos Poderes Públicos na esfera social restringe-se ao provimento de uma "rede de proteção social" ante as incertezas da atividade econômica, uma rede que é subsidiária no sentido de operar como um seguro contra o fracasso do indivíduo que deve, em regra, ser exclusivamente responsável pela própria sina. Apesar dessa convergência nos resultados, entretanto, a descrição que o artigo do Prof. Faria faz da referida migração não apela para qualquer conteúdo ideológico. As suas causas não são culturais, mas políticas e, sobretudo, econômicas. O encolhimento do conjunto das alternativas de decisão factíveis decorreria das restrições estabelecidas pela globalização econômica, vale dizer, por transformações estruturais do ambiente político com as quais o poder estatal teria que se confrontar como dado exógeno à situação de decisão.

Nesse sentido, a substituição da universalização pela focalização seria justificável racionalmente como produto de um autoesclarecimento que esteriliza propostas rivais e críticas puramente normativas. Diante de uma realidade econômica pouco controlável e da falta de condições materiais para a generalização dos benefícios almejados, desaparece a pecha neoconservadora que a referida substituição carregaria consigo sob circunstâncias diferentes. Com isso, a questão é despolitizada e se 
converte em um problema técnico de adequação teleológica delimitado pelo objetivo da "maximização da eficiência alocativa de recursos escassos" (FARIA, 2009: 319).

\section{O PROBLEMA DA INEFICÁCIA DOS DIREITOS SOCIAIS UNIVERSAIS}

O caso brasileiro é teoricamente interessante também por outras razões. Quando se conjectura que, no Brasil, a "substituição da ideia de direitos universais por estratégias de focalização” é parte de um cenário pós-crise que é verossímil, sobretudo em virtude da ausência dos custos sociopolíticos associados a um movimento de desinstitucionalização jurídica, está-se supondo que as promessas normativas contidas no texto da Constituição Federal quanto à realização de direitos sociais universais não são apenas descumpridas de modo sistemático. Além disso, a conjectura assume que esse descumprimento pode ser tal que subtrai força jurídica às referidas promessas. Esta é uma suposição não trivial sobre a qual vale pausar um instante.

Um dos mais produtivos achados da Teoria Pura do Direito está na observação de que, para toda norma jurídica N, um "mínimo de eficácia” é condição de sua validade. Há alguns anos, ao propor uma caracterização pragmática da norma jurídica a partir de uma releitura heterodoxa da correspondente definição kelseniana (SCHUARTZ, 2005), sugeri que essa relação de condicionamento entre eficácia e validade podia ser naturalmente inferida de um conceito de norma que a descreve como situação social na qual a um determinado conteúdo semântico é associada, desde uma perspectiva socialmente generalizada, à força própria de um "dever-ser objetivo". 3

Se pensarmos no conceito de validade como aplicável a situações sociais em que o sentido pragmático de um dever-ser objetivo (“dever-ser obj”) é corretamente atribuído a uma determinada decisão a partir de uma perspectiva socialmente generalizada, então poderemos enxergar no mínimo de eficácia kelseniano o estado de coisas que evidencia, complementarmente a existência de um "fundamento de validade", a justificativa para a referida atribuição. A capacidade de fazer realizar, inclusive mediante o uso da força, o conteúdo semântico da decisão a que é atribuído o sentido pragmático de norma jurídica figura, portanto, na qualidade de elemento constitutivo desse sentido, como condição para que se possa avaliar como correto ou incorreto o tratamento de algo como possuindo esse sentido. Porém, trata-se de uma condição de natureza distinta daquela representada pela possibilidade (também implicada pela natureza específica do sentido pragmático própria à norma jurídica) de fornecer as razões que apontam para a existência de uma autorização normativa para a decisão. Kelsen estava correto ao estabelecer uma distinção entre essas duas diferentes condições de sucesso pragmático, correspondente à diferenciação entre os significados que assumem, nesse contexto, as questões do "fundamento de validade" e da "condição de validade". Tanto a possibilidade de explicitação da autorização normativa upstream como a capacidade de garantir o mínimo 
de eficácia downstream são elementos constitutivos do conceito de validade jurídica, uma vez que são ambos constitutivos do conceito mais elementar de norma jurídica - ainda que a contribuição de cada um para a determinação do conteúdo semântico do referido conceito seja completamente diferente. No nível mais elementar, a existência de uma norma jurídica dependerá da instituição e estabilização de uma situação social em que, a uma determinada decisão for atribuída uma perspectiva socialmente generalizada, um sentido pragmático que exibir os atributos específicos de um dever-ser $\mathbf{o b j}$. Sem essa instituição e estabilização tenderá a desaparecer por inteiro a situação social apenas diante da qual estar-se-á autorizado a indagar acerca da adequação do tratamento efetivo de algo como norma jurídica, isto é, acerca da validade da norma jurídica assim instituída. ${ }^{4}$

Quando os fatos são tais que inviabilizam aquilo que o ato de vontade comanda ao negarem as condições para sua realização, caberia logo questionar se seria plausivelmente justificável a atribuição, ao ato de vontade, da "força ilocucionária" (sentido pragmático) de um dever-ser obj. Esse questionamento está baseado na seguinte ordem de ideias: (a) o tratamento, de uma perspectiva socialmente generalizada, do

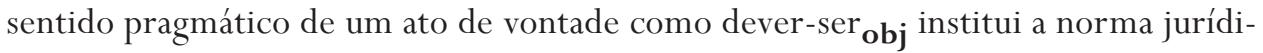
ca; (b) a atribuição desse sentido pragmático específico implica que se está presumindo que aquele a quem se imputa o ato de vontade seja alguém (b.i) que pode prestar contas em relação à autorização normativa que lhe confere legitimidade para prescrever a terceiros, do modo como o fez, como estes deveriam comportar-se, e (b.ii) que é capaz de tornar verdadeiro em um número razoável de casos particulares, por si ou por meio de um "aparato coercitivo" (ao qual poderá estar funcionalmente ligado, por exemplo, em razão do cargo), se necessário recorrendo ao uso da força, o conteúdo semântico associado ao ato de vontade; e (c) o tratamento efetivo, de uma perspectiva socialmente generalizada, do sentido pragmático de um ato de vontade como dever-ser obj será justificado, e a norma daí resultante será válida, se e só se as duas condições, (b.i) e (b.ii), forem verdadeiras, vale dizer, se e somente se for verdadeiro que (b.i') aquele a quem se imputa o ato de vontade estiver realmente autorizado a determinar como deve ser o comportamento dos outros da maneira como o fez, e (b.ii') este alguém (ou outro alguém designado para o mesmo fim) for realmente capaz de garantir ao ato de vontade - ou melhor, ao comportamento que foi ordenado por meio do ato de vontade -, um “mínimo de eficácia”.

Por outro lado, decisões adotadas pelas pessoas juridicamente competentes e em conformidade com os procedimentos aplicáveis quase sempre produzirão algum impacto na realidade social e neste sentido serão sempre "eficazes". Tal impacto, porém, pode não ser aquele materialmente implicado pelo conteúdo semântico da decisão ou norma geral que aquela pretende ter "aplicado" a um caso concreto. A realidade que sistematicamente sabota um objetivo nominalmente previsto em uma 
norma geral sabota, simultaneamente, as decisões individuais que a invocam nominalmente como fundamento para a solução de litígios particulares. A impotência da norma diante da realidade comunica-se às decisões que almejam aplicá-la, que serão ineficazes no sentido da concretização da norma e nos seus próprios termos, mas “eficazes”, no sentido da produção de um estado de coisas não autorizado e possivelmente ilegítimo.

O descumprimento de promessas nominais de garantia jurídica de direitos sociais universais é um exemplo particularmente informativo da possibilidade de produção desse duplo efeito jurídico. Considere-se, ilustrativamente, a hipótese da criação e estabilização de privilégios para um determinado conjunto de pessoas, resultantes de decisões judiciais que lhes foram favoráveis e que se fundamentam em liberdades ou direitos nominalmente universais, mas cuja fruição generalizada efetivamente dependa da provisão de condições materiais inexistentes. Nesse caso, a ineficácia social da proposta normativa de conteúdo universal pode (i) afetar sua validade jurídica (via perda da justificativa para o tratamento efetivo do correspondente ato de vontade como algo que exibiria o sentido pragmático de um dever-ser obj), e sua existência como norma jurídica (via extinção desse tratamento efetivo desde uma perspectiva socialmente generalizada); e, simultaneamente, (ii) induzir o aparecimento de outra norma jurídica agora "implícita” na prática de implementação normativamente distorcida -, da referida promessa nominal, de uma norma com conteúdo semântico não universal delineado pelas características dos privilégios pessoais criados e estabilizados por meio dessa prática.

Note-se que as consequências desses movimentos de reclassificação pragmática são função dos tipos de explicação pertinentes a cada caso particular de ineficácia social empiricamente verificável. Basicamente, poder-se-ia agrupar esses tipos em duas grandes categorias. A primeira categoria refere-se às explicações que reconduzem a ineficácia da norma à ausência de "vontade política” para sua aplicação não distorcida, supondo que estariam presentes os pressupostos materiais para essa aplicação. A segunda, por sua vez, nega essa suposição e explica a ineficácia da norma recorrendo justamente à ausência dos referidos pressupostos materiais. Se a explicação para a ineficácia de uma norma remeter, exclusivamente, a fatores controláveis por decisões políticas, a atitude normativamente mais apropriada diante da constatação do fato da ineficácia será, ceteris paribus, a recusa ao aprendizado com a frustração da expectativa normativa inicial, seguida do esforço no sentido da adoção das medidas políticas ou administrativas necessárias para fazer valer o conteúdo semântico exibido pelo texto normativo em questão. A factibilidade política da produção das condições necessárias para conferir força jurídica a esse conteúdo zela pela não irracionalidade da atitude. Do ponto de vista normativo, isto bastaria para agarrar-se à expectativa e resistir à realidade que promove a sua frustração. A situação é distinta na outra hipótese, isto é, se a explicação para a ineficácia decorre 
da constatação de que faltam os pressupostos materiais para o cumprimento da promessa veiculada no texto normativo e esses pressupostos não podem ser garantidos por ações disponíveis aos agentes políticos competentes. Nesta hipótese, a insistência na expectativa e a resistência à realidade que a frustra tornam-se irracionais, operando na contramão do política e juridicamente possível. Quando a promessa é irrealizável, as demandas por seu cumprimento aproximar-se-ão, na prática, das táticas ideológicas de acobertamento e justificação de distorções e privilégios instituídos pela sua pseudossatisfação.

Os fatores determinantes do evento de substituição prognosticado pelo Prof. Faria são elementos de explicações dessa segunda categoria. Entre os dois supostos utopismos: o do controle pelo Estado nacional dos efeitos localmente produzidos pelo funcionamento da economia globalizada; e o da institucionalização de um welfare state transnacional, há somente o espaço real das alternativas de decisão politicamente factíveis (a países como o Brasil), as quais se apresentam, no âmbito das políticas sociais, como pares formados, de um lado, por programas assistencialistas focalizados, e de outro, por acordos envolvendo grupos de interesse e políticos que entre si barganham distribuições de recursos públicos não previamente comprometidos.

Minha convicção pessoal é que esta prognose lança o dardo longe demais, e que a questão teoricamente importante, na verdade, é qual consequência normativa deveríamos extrair do nosso desconhecimento objetivo acerca de onde nos encontramos com respeito à diferença entre o politicamente factível e o politicamente não factível (SCHUARTZ, 2002). Seja como for, a resposta a essa questão passa pela exploração das implicações do cenário mais pessimista do ponto de vista da plena realização do ideal democrático-participativo, as quais devem incluir as implicações para as autonomias pública e privada dos cidadãos associadas à limitação da política social ao conjunto das combinações entre focalização e contratualização de seus benefícios. Antes de iniciar sua discussão na seção 3, contudo, e avançar para o tema das implicações associadas ao referido estado de desconhecimento objetivo, será útil tornar explícito o que tal limitação pode significar em termos do status jurídico das promessas enunciadas nos textos normativos que expressamente absorveram a "ideia de direitos [sociais] universais".

Focalização e contratualização são estratégias particularistas de política social. A concessão dos benefícios aos recipientes, em ambos os casos, é dependente da pertinência dos últimos a conjuntos restritivos de cidadãos. Na focalização, a relação de pertinência é usualmente definida em função de critérios de renda, ao passo que, na contratualização, o beneficiário é membro do grupo que figura como parte do acordo que prevê as obrigações positivas e negativas do Estado, com os seus benefícios definidos em função do poder de barganha do grupo a que ele pertence, comparativamente ao poder de barganha das outras partes contratantes. Indivíduos que não pertencerem a quaisquer desses conjuntos estarão fora do alcance da política social 
e entregues ou à própria sorte nos mercados de trabalho, ou, na outra ponta, ao gozo das benesses e comodidades oferecidas pelos planos privados de seguridade e assistência. Essa particularização dos meios parece apenas alinhar-se com uma universalização dos fins, isto é, com a efetiva garantia de oportunidades e condições de vida materialmente dignas para a totalidade dos cidadãos, assumindo-se que os eventuais espaços vazios deixados pelo poder estatal serão preenchidos por externalidades positivas produzidas pelas decisões de agentes econômicos que visam maximizar suas preferências individuais nos seus respectivos mercados de atuação externalidades a serem posterior e estavelmente usufruídas pelas pessoas as quais nem Estado, nem mercado, contemplarem diretamente com a referida garantia.

Aqueles que quiserem acreditar na plausibilidade dessa versão extrema do ideal da "justiça de mercado", que acreditem. Os demais haverão de confiar que a particularização dos instrumentos de política social pode cambiar substancialmente o conteúdo semântico do que teria sido de fato institucionalizado juridicamente com a afirmação normativa dos direitos sociais universais. O que, nominalmente, deveria valer para todos, valerá só para alguns, e ante a experiência sistemática da frustração, a razão determinará o aprendizado e a adaptação, não a luta pela confirmação do que se esperava normativamente. A falta de eficácia da promessa universal funciona, sob as condições aqui supostas, como produtora do duplo efeito jurídico a que se fez menção supra, a saber, a extinção da juridicidade da norma universal, de um lado, e o surgimento da norma jurídica (não universal) que estará implícita na prática sistematicamente viesada de implementação da norma universal pelos sujeitos competentes, de outro lado.

A dificuldade de operacionalização empírica das distinções analíticas introduzidas nesta seção não deveria nos fazer desviar o olhar dessa conclusão. A observação de que decisões judiciais são proferidas e benefícios são administrativamente concedidos em nome de princípios universais não atesta a eficácia dos princípios em questão. Ausentes os pressupostos de fato para o efetivo cumprimento da promessa veiculada pelo princípio, a leitura correta dessas decisões e atos administrativos, possivelmente, não será a que lhes interpreta como aplicações particulares de uma norma jurídica universal (pois essa norma poderá ter simplesmente deixado de existir como norma jurídica), mas sim, da norma não universal que a proclamação nominal do princípio, combinada com a impossibilidade material da sua plena realização e, não obstante, com as tentativas de realizá-lo, ajudaram a elevar ao plano do Direito vigente.

\section{DesuniversalizaçÃo de Direitos SOCIAIS E liberdadeS INDIVIDUAiS}

Os efeitos jurídicos esperados da particularização da política social não se limitam somente à desuniversalização do conteúdo semântico dos direitos sociais. Em virtude 
da posição desses direitos no espaço dos direitos fundamentais, essa desuniversalização afeta também os conteúdos semânticos dos direitos subjetivos relativos às liberdades pública e privada dos indivíduos. A ideia de que a efetiva garantia de determinados direitos sociais seria condição necessária para a generalização das liberdades individuais - a qual já havia comparecido decisivamente na reconstrução histórico-sistemática de Marshall -, fixou-se no pensamento social não conservador da segunda metade do século 20, incorporou-se ao estoque de intuições normativas das camadas mais progressistas da sociedade moderna (sobretudo nas democracias liberais do ocidente) e foi absorvida pela dogmática jurídico-constitucional na afirmação do “mínimo existencial como conteúdo essencial dos direitos fundamentais" (LOBO Torres, 2008).

$\mathrm{Na}$ teoria social de Jürgen Habermas, para ficarmos com um exemplo, os direitos sociais são concebidos como elementos constitutivos do "sistema de direitos", isto é, de um conjunto de direitos subjetivos cujo reconhecimento positivo é condição necessária para a legitimidade de qualquer ordem jurídica (HABERMAS, 1994). $\mathrm{Na}$ concepção habermasiana, a inserção dos direitos sociais no sistema de direitos justifica-se relativamente aos direitos "absolutos", à autonomia pública e à autonomia privada, mas tal relatividade afirma-se no sentido normativamente qualificado de que os direitos absolutos implicam a presença dos "direitos relativos" como condição materialmente necessária para a sua fruição. ${ }^{5}$ Mais precisamente, direitos sociais servem para garantir à totalidade dos cidadãos as condições materiais para a sua autodeterminação "ético-existencial”, a qual, por sua vez, é condição para sua autodeterminação política.

A implementação sistematicamente viesada de direitos sociais universais é, assim, capaz de contaminar os demais tipos de direitos subjetivos cujo exercício depende da sua institucionalização. A desuniversalização dos primeiros é seguida pela desuniversalização dos últimos. Sem um acesso juridicamente assegurado a benefícios materiais, proteções e oportunidades, que somente o reconhecimento positivo de direitos sociais poderá prover, a capacidade para exercer as liberdades nominalmente previstas no texto constitucional não se generaliza entre os cidadãos. As liberdades individuais desprendem-se da cidadania e passam a ter a sua concretização dependente de outras variáveis, como poder de barganha em negociações políticas e dinheiro.

A transformação de liberdades em privilégios é certamente a mais inquietante das consequências associadas à particularização das políticas sociais. Ela ocorre por meio de mecanismo idêntico ao responsável pela desuniversalização dos direitos sociais: a falta de eficácia da promessa universalista vai corroendo seu status de norma jurídica, ao mesmo tempo em que seu cumprimento sistematicamente distorcido vai cristalizando uma norma jurídica com conteúdo semântico diferente (não universalista). O conjunto dos indivíduos com direito às liberdades passa, em virtude desse duplo movimento, a ser menor do que o conjunto de todos os cidadãos. 
Apesar da mencionada identidade, a particularização das políticas sociais não está para a desuniversalização dos direitos sociais exatamente assim como a última está para a desuniversalização das liberdades fundamentais. A institucionalização jurídica de direitos sociais universais é condição materialmente necessária para a institucionalização jurídica de liberdades fundamentais universais, mas essa relação não se encontra refletida em uma correspondência ponto a ponto no plano individual. Isso significa que alguém pode gozar de liberdades fundamentais sem ser titular de direitos sociais (p.ex., os cidadãos mais ricos que satisfaçam todas as suas necessidades de consumo via mercado), e vice-versa: algum titular de direitos sociais pode não gozar de liberdades fundamentais (p.ex., os recipientes de transferências assistencialistas desprovidos de acesso a serviços públicos de educação que cumpram requisitos mínimos de qualidade). A questão é relevante na medida em que a ausência dessa correspondência influi decisivamente sobre o alinhamento dos incentivos dos indivíduos para reivindicar (ou preservar) direitos de um ou outro tipo. Por exemplo, uma intervenção estatal restritiva da liberdade privada de um dado conjunto de indivíduos possivelmente enfrentará forte oposição dos indivíduos desse conjunto, mesmo que seja estritamente necessária para assegurar direitos sociais básicos a indivíduos pertencentes a grupos socialmente desfavorecidos.

Obviamente, a avaliação adequada das eventuais propostas de solução normativa para esse e semelhantes conflitos distributivos dependerá de onde situarmos os limites do politicamente factível. A avaliação de uma proposta de solução normativa para um dado conflito distributivo, supondo-se que não haveria como gerar os recursos suficientes para a satisfação das demandas de todos os interessados, terá, provavelmente, que ser diferente da avaliação da mesma proposta, se assumirmos que vale a situação contrária. De fato, se, na primeira hipótese, a aceitabilidade racional, por exemplo, de propostas de solução distributivas universalistas e igualitárias está trivialmente prejudicada, isso não se verifica na segunda hipótese, na qual a factibilidade política da proposta ampara a sua justificação normativa e torna possível a sua aceitação racional (ao menos no que diz respeito à garantia jurídica generalizada de direitos fundamentais). Ocorre que, também com relação ao problema da ótima alocação de liberdades individuais entre os membros de uma comunidade jurídica, a posição correta dos referidos limites não é conhecida objetivamente. Nós simplesmente ignoramos, diante desse problema, de qual lado da diferença entre politicamente factível e politicamente não factível nós nos encontramos. Consequentemente, tampouco sabemos se o que institucionalizamos juridicamente ao veicularmos a promessa de universalização dessas liberdades em um dado texto normativo, e agirmos no sentido da sua realização, é uma norma que garante direitos de conteúdo universal ou uma que estabelece privilégios para conjuntos seletivos de cidadãos.

O conhecimento da nossa falta de conhecimento acerca da garantia das condições econômicas necessárias para a universalização dos direitos fundamentais ${ }^{6}$ lança uma 
luz problematizadora sobre o ensaio do Prof. Faria, que é bastante rica em implicações. Com a dúvida a respeito da factibilidade política da pretensão normativa universalista vem, em princípio, a sustentabilidade dessa pretensão como definidora de um objetivo político que não podemos desqualificar como inatingível. A irracionalidade dos esforços para fins da implementação de um objetivo, que sabemos ser inviável, deixa de se verificar perante o estado de dúvida com relação a essa impossibilidade e o conhecimento da sua natureza estrutural. É verdade que, na dúvida, a presença das motivações requeridas para que esses esforços coletivos sejam empreendidos e organizados dependerá da formação de estoques subjetivos de confiança que, por hipótese, não serão passíveis de geração por argumentos racionais. Entretanto, assumindo que o objetivo a perseguir conte com apoio suficiente no interior da coletividade, essas lacunas de fundamentação racional poderão ser preenchidas pela crença de que, na ausência desses esforços, a dúvida transformar-se-á em certeza de que o resultado não será alcançado.

O conhecimento do desconhecimento dos limites do politicamente factível remete, juridicamente, ao caráter indeterminado do conteúdo semântico das normas instituidoras de direitos fundamentais, tornando explícito que as suas positivação e implementação têm consequências incertas. Os riscos da constituição e do aprofundamento de privilégios não podendo ser descartados nem mensurados, uma opção esclarecida por essas positivação e implementação irá se apresentar como uma aposta que topou enfrentar estes riscos em vez dos riscos da omissão política diante de um futuro que não se quer esperar, passivamente, que venha assim como vem. Sob condições de ignorância, a esperança transforma-se em um fator racional de determinação da ação política, e não há como excluir a possibilidade de que ela sirva de catalisadora de uma dinâmica que culmine na produção das condições de realização do seu próprio objeto.

Nesse sentido, a prognose da "substituição da ideia de direitos sociais universais" deveria incluir a reflexão sobre os efeitos futuros, empíricos e normativos, associados ao reconhecimento generalizado do seu caráter puramente especulativo. Em outras palavras, espera-se que o prognóstico contenha as respostas às seguintes perguntas: como deveriam reagir os indivíduos a tal proposta de substituição, supondo-se que sabem que não sabem se as condições materiais para a institucionalização jurídica de direitos sociais universais poderão ser criadas e estabilizadas por meio da política?, E como reagirão os indivíduos a essa proposta de substituição, nas mesmas circunstâncias?

A menos que o observador que enuncia a prognose recuse essa suposição atribuindo a si mesmo, no presente, e aos atores envolvidos, no futuro, o conhecimento da não factibilidade da criação e estabilização, o enfrentamento dessas questões seria parte constitutiva da justificação da prognose como conjectura plausível. E o que a leitura do artigo do Prof. Faria nos sugere é, justamente, a pressuposição do autor de que essa atribuição seria justificada com relação ao destino das políticas sociais universalizantes. 
Conforme exposto, essa é uma pressuposição questionável. O que se pode afirmar da relação entre internacionalização dos mercados e possibilidade de intervenção estatal no domínio econômico é que a primeira poderá reduzir substancialmente a segunda. Daí a afirmação de que essa redução é tal que torna impossível a institucionalização jurídica de direitos sociais universais emancipatórios, vai um salto que esteriliza o controle objetivo de qualquer pretensão de conhecimento. Se for verdadeira a hipótese de que sabemos, ou deveríamos saber, que não sabemos se as condições necessárias para a institucionalização jurídica de direitos sociais universais podem ou não ser criadas e estabilizadas via política interna, então o prognóstico da substituição do ideal normativo da implementação de tais direitos perde sua plausibilidade. Diante das assimetrias de renda, oportunidades e riscos observáveis globalmente, bem como da fragilidade teórica e normativa das propostas não intervencionistas de reação às mesmas, é difícil acreditar que as demandas no sentido da institucionalização jurídica e ampliação de direitos protetivos para todos sejam superadas, na arena política, pelas demandas dos seus opositores; e mais difícil ainda convencer-se, racionalmente, de que os argumentos normativos disponíveis para bancar as demandas no primeiro sentido seriam efetivamente desbancados por aqueles disponíveis para suportar demandas no sentido oposto. Novamente, o risco da consolidação de privilégios em favor de agentes dotados de maior capacidade de reivindicação, decorrente do atendimento das demandas do primeiro tipo, parece ser um preço que, socialmente, vale a pena pagar pela consciência de que se tentou o possível para evitar uma situação ainda menos equitativa do ponto de vista distributivo.

\section{Conclusão}

Prognoses, mesmo que enunciadas sob confessada ignorância, não são atos de fala desprovidos de consequências. A limitação autoimposta nas pretensões de conhecimento do autor de uma prognose no instante em que ressalva seu caráter especulativo, não retira desta o potencial de afetar interesses e influenciar comportamentos. Sobretudo quando os seus destinatários estão convictos de que a ressalva se aplica a todos que se aventurarem por caminhos similares, a prognose pode adquirir força determinante como orientação para expectativas e ações. Prognoses que incluem, entre suas premissas, afirmações sobre aquilo que seria politicamente possível, fornecem exemplos ilustrativos de como as ações desencadeadas a partir das mesmas poderiam contribuir para a produção dos fatos que as confirmem ou desconfirmem.

A hipótese da substituição da ideia de direitos sociais universais por estratégias de focalização nos indivíduos mais carentes da população é uma prognose acerca da política social pós-crise que serve, nesse contexto, como um interessante caso particular. Supondo que sabemos que não sabemos se as condições materiais necessárias para institucionalizar juridicamente os referidos direitos podem ser criadas e estabilizadas por 
meio da política estatal, parece-me razoável imaginar que essa seja uma prognose que aciona suas próprias condições de desconfirmação. Feita essa suposição, a antecipação, pelos destinatários, dos efeitos empíricos e respectivas implicações normativas associados ao abandono do ideal dos direitos sociais universais, pode por em movimento iniciativas políticas que mirem e, eventualmente, resultem na institucionalização jurídica do que, segundo a prognose, viria a ser futuramente abandonado.

O que podemos esperar da adoção dessas iniciativas, não obstante, é um desfecho indeterminado da perspectiva da institucionalização dos direitos fundamentais, localizado em algum ponto do intervalo limitado superiormente pela universalização desses direitos em uma direção emancipatória e, inferiormente, pela constituição de estruturas jurídicas que sustentam o aparecimento de novos e a reprodução de antigos nichos para privilégios e exercícios de poder ilegítimo na sociedade. Espaço reservado para uma esperança pode ser pouco se comparado com o sentido literal dos textos normativos correspondentes, mas talvez seja tudo que possamos justificadamente - e precisemos - assumir para cobrarmos, uns dos outros, comprometimento e empenho para fazer cumprir esse sentido nos limites do que acreditarmos ser possível.

: ARTIGO APROVADO (01/10/2009) : RECEBIDO EM 05/06/2009

\section{NOTAS}

1 Disponível em: http://www.ilo.org/global/About_the_ILO/Mainpillars/Socialprotection/lang —en/index.htm.

2 Para uma análise empírica das dificuldades relacionadas à fiscalização da implementação dos programas condicionais previstos no Bolsa-Família, bem como de algumas das suas implicações políticas, ver Estrella e Ribeiro, 2008.

3 O significado das expressões "força" ou "sentido pragmático" refere-se, neste contexto, à ação específica socialmente atribuída a alguém ao fazer uso da linguagem em uma determinada situação comunicativa (p.ex., uma asserção, uma pergunta, uma prescrição, etc.). Grosso modo, a força ou o sentido pragmático que são característicos de um dever-ser objetivo do tipo jurídico (isto é, de uma norma jurídica) consistem em uma forma particular de "sucesso" conquistado por um dado comportamento ao qual se atribuem essa força ou esse sentido pragmático, qual seja: o sucesso na obtenção do reconhecimento socialmente generalizado da capacidade de obrigar outras pessoas a fazer ou deixar de fazer alguma coisa (ou então, de conferir uma capacidade similar a outras pessoas).

4 Sabidamente, Kelsen não faz essa diferenciação e identifica explicitamente existência e validade da norma jurídica. Para uma exposição das razões pelas quais entendo que se trata de uma assimilação inadequada do ponto de vista teórico e não logicamente implicada pela concepção kelseniana da norma como "esquema de interpretação", ver Schuartz, 2005.

5 De acordo com Habermas, esses direitos relativos devem dar cobertura a exigências de "segurança social" tanto na dimensão da garantia das condições materiais para o exercício dos direitos absolutos às liberdades privada e pública, 
como também, na dimensão da proteção contra os riscos tecnológicos e ecológicos a que estão expostos os indivíduos que vivem em uma sociedade moderna. A respeito, ver Habermas, 1994, p. 156-157; 503-504.

6 Não é possível, neste espaço, demonstrar-se a plausibilidade da afirmação do desconhecimento objetivo a respeito da criação e estabilização das condições econômicas necessárias para a universalização dos direitos sociais e, por essa via, a universalização das liberdades fundamentais (especialmente em países com perfis de distribuição de renda semelhantes ao brasileiro). Para argumentos nessa linha baseados numa descrição do sistema econômico da sociedade moderna que o caracteriza como estrutural e conjunturalmente instável, e significativamente imprevisível quanto às futuras trajetórias das variáveis mais relevantes para a referida universalização, ver Schuartz, 2002.

\section{REFERÊNCIAS BIBLIOGRÁFICAS}

BEATTIE, R. Social protection for all: But how? International Labour Review, v. 139, n. 2, p. 129-148, 2000. BECK, U.; BONSS, W.; LAU, C. The Theory of Reflexive Modernization: Problematic, Hypotheses and Research Programme. In: Theory, Culture \& Society, v. 20, n. 2, p. 1-33, 2003.

CASTLES, F. The future of the welfare state: crisis myths and crisis realities. International Journal of Health Services, v. 32, n. 2, p. 255-277, 2002.

CLAYTON, R.; PONTUSSON, J. Welfare-State Retrenchment Revisited: Entitlement Cuts, Public Sector Restructuring, and Inegalitarian Trends in Advanced Capitalist Societies. World Politics, v. 51, n. 1, p. $67-$ 98, 1998 .

COX, R. H. The Consequences of Welfare Reform: How Conceptions of Social Rights are Changing. Journal of Social Policy, v. 27, n. 1, p. 1-16, 1998.

DEACON, B. From "Safety Nets" Back to "Universal Social Provision”. Is the Global Tide Turning? Global Social Policy, v. 5, n. 1, p. 19-28, 2005.

DE DONDER, P.; HINDRIKS, J. The Political Economy of Targeting. Public Choice, v. 95, p. 177-200, 1998. ELLISON, N. Beyond universalism and particularism: rethinking contemporary welfare theory. Critical Social Policy, v. 19, n. 1, p. 57-85, 1999.

ESPING-ANDERSEN, G. The Three Worlds of Welfare Capitalism. Princeton: University Press, 1990.

ESTRELLA, J.; RIBEIRO, L. M. O Programa Bolsa-Família e as condicionalidades de saúde em nível municipal: um programa populista ou estrutural? Sinais Sociais, v. 2, n. 6, p. 12-43, 2008.

Faria, José Eduardo. Poucas certezas e muitas dúvidas: o direito depois da crise financeira. Revista DIREITO GV. São Paulo: DIREITO GV, v. 5, n. 2, jul-dez 2009, pp.297-324.

HABERMAS, J. Faktizität und Geltung. Beiträge zur Diskurstheorie des Rechts und des demokratischen Rechtstaats, Suhrkamp, 1994.

KERSTENETZKY, C. L. Políticas Sociais: focalização ou universalização? Revista de Economia Política, v. 26, n. 4, p. 564-574, 2006.

KORPI, W. Welfare-State Regress in Western Europe: Politics, Institutions, Globalization, and Europeanization. Annual Review of Sociology, v. 29, p. 589-609, 2003.

KORPI, W., PALME, J. New Politics and Class Politics in the Context of Austerity and Globalization: Welfare State Regress in 18 Countries 1975-1995. American Political Science Review, v. 97, p. 425-446, 2003.

KOSTER, F. The Welfare State and Globalization: Down and Out or Too Though to Die? International Journal of Social Welfare, v. 18, p. 153-162, 2009.

LOBO TORRES, R. O mínimo existencial como conteúdo essencial dos direitos fundamentais. In: SOUZA NETO, C. P.; SARMENTO, D. (Coord.) Direitos sociais. fundamentos, judicialização e direitos sociais em espécie. Rio de Janeiro: Lumen Juris, p. 313-339, 2008.

MANOW, P.; VAN KERSBERGEN, K. Religion and the Western Welfare State - The Theoretical Context. In: VAN KERSBERGEN, K.; MANOW, P. (Ed.) Religion, Class Coalitions and Welfare State Regimes. Cambridge University Press, p. 4-37, 2009.

MARShall, T. H. Citizenship and Social Class. Class, Citizenship and Social Development. Doubleday, p. 65 122, 1964.

MKANDAWIRE, T. Targeting and Universalism in Poverty Reduction. In: OCAMPO, J. A.; KHAN, S. (Ed.)

Policy Matters: Economic and Social Policies to Sustain Equitable Development. Zed Books, p. 305-333, 2007.

OFFE, C. 1981. Some Contradictions of the Modern Welfare State. Praxis International, v. 3, p. 219-229, 1981. 
PALIER, B. 2006. Beyond Retrenchment: Four Problems in Current Welfare State Research and One Suggestion on How to Overcome Them. In: PIERSON, C.; CASTLES, F. (Ed.) TheWelfare State Reader. 2. ed. Polity Press, p. 358-374, 2006.

PIERSON, P. Dismantling the Welfare State? Reagan, Thatcher, and the Politics of Retrenchment. Cambridge University Press, 1994.

. The New Politics of the Welfare State. World Politics, v. 48, n. 2, p. 143-179, 1996.

2001. Coping with Permanent Austerity: Welfare State Restructuring. In: Affluent Democracies. Révue Française de Sociologie, vol. 43, n. 2, p. 369-406, 2001.

SCHARPF, F. W. 2002. Globalization and the Welfare State: Constraints, Challenges and Vulnerabilities. In: SIGG, R.; BEHRENDT, S. (Ed.) Social Security in the Global Village. Transaction Publishers, p. 85-116, 2002.

SCHUARTZ, L. F. Die Hoffnung auf radikale Demokratie. Fragen an die Theorie des kommunikativen Handelns. Peter Lang, 2002.

A práxis recalcada na teoria da norma de Hans Kelsen. In: SCHUARTZ, L. F. Norma, contingência e racionalidade. Estudos preparatórios para uma teoria da decisão jurídica. São Paulo: Renovar, p. 1-61, 2005. SEN, A. The Political Economy of Targeting. In: VAN DE WALLE, D.; NEAD, K. (Ed.) Public Spending and the Poor: Theory and Evidence. Johns Hopkins University Press, p. 11-24, 1995.

SKOCPOL, T. Universalism within Targeting: Politically Viable Policies to Combat Poverty Within the United States. In: JENCKS, C.; PETERSON, P. E. (Ed.) The Urban Underclass. Brookings Institution, p. 411-436, 1991. TENDLER, J. 2004. Why Social Policy is Condemned to a Residual Category of Safety Nets and What to Do About it. In: MKANDAWIRE, T. (Ed.) Social Policy in a Development Context. Palgrave MacMillan, p. 119-142, 2004.

TOWNSEND, P. From Universalism to Safety Nets: The Rise and Fall of Keynesian Influence on Social Development. In: MKANDAWIRE, T. (Ed.) Social Policy in a Development Context. Palgrave MacMillan, p. 37-62, 2004.

VAN KERSBERGEN, K. The declining resistance of welfare states to change? In: KUHNLE, S. (Ed.) The Survival of the European Welfare State. Routledge, p. 19-36, 2000.

\author{
Luis Fernando Schuartz
}

Praia do Botafogo, 190, $13^{\circ}$ andar
Botafogo - 22250-900 PROFESSOR TITULAR DA FGV DIREITO RIO |

Rio de Janeiro - RJ - Brasil

luis.schuartzlafgv.br 